\title{
1 Impact of fungal contamination of wheat on grain quality
}

\section{2 criteria}

3 Marcus Schmidta ${ }^{\mathrm{a}, \mathrm{c}}$, Stefan Horstmann ${ }^{\mathrm{a}}$, Lorenzo De Colli ${ }^{\mathrm{b}}$, Martin Danaher ${ }^{\mathrm{b}}$, Karl

4 Speer $^{\mathrm{c}}$, Emanuele Zannini ${ }^{\mathrm{a}}$ and Elke K. Arendt ${ }^{\mathrm{a} *}$

5

$6 \quad{ }^{a}$ School of Food and Nutritional Sciences, University College Cork, Ireland.

$7{ }^{b}$ Food Safety Department, Teagasc Food Research Centre, Ashtown, Dublin 15, 8 Ireland.

$9 \quad{ }^{\mathrm{C}}$ Food Chemistry, Technische Universität Dresden, Germany.

$10{ }^{*}$ Corresponding author: Mailing address; School of Food and Nutritional Sciences,

1116 University College Cork, Western Road, Cork, Ireland. Phone: +353-21-4902064.

12 Fax: +353-17 214270213. Email: e.arendt@ucc.ie

13 Keywords: Fusarium culmorum, Wheat quality, Storage, Mycotoxins

14 Chemical compounds studied in this article:

15 Ergosterol (PubChem CID: 247705); Deoxynivalenol (PubChem CID: 40024); 16 Zearalenone (PubChem CID: 5281576); 3-Acetyl deoxynivalenol (PubChem CID: 17 104759); Deoxynivalenol 3-glucoside (PubChem CID: 71312510); Gliadin (PubChem 18 CID: 17787981); Sucrose (PubChem CID: 3036169); Maltose (PubChem CID: 6255); Glucose (PubChem CID: 5793); Arabinose (PubChem CID: 66308) 
The aim of this study was to investigate the spread of minimal, field born Fusarium infections in wheat during storage and the resulting impact on grain quality. Therefore, F. culmorum was chosen as the representative strain. Wheat grains were artificially infected and stored for 6 weeks in a model system. To estimate the fungal growth, the ergosterol content was determined as this correlates with the fungal biomass. Ergosterol levels revealed a rapid spread of the infection during storage conditions. Furthermore, analysis of nine mycotoxins showed that Deoxynivalenol and Zearalenone occurred in concentrations exceeding the maximum residue limits.

Scanning electron microscopy illustrated the penetration of the fungus into the endosperm and showed the degradation of important seed constituents, such as starch and storage proteins. This is mainly due to the increased activity of proteases and amylases by the fungal metabolism. The results of this study show how small levels of field contamination can easily spread during storage and so lead to significant losses in grain quality and present a potential consumer health hazard. Thus, it demonstrates the need to develop efficient methods for crop protection during storage, without compromising the quality.

\section{ABBREVATIONS}

3-ADON: 3-Acetyldeoxynivalenol, DAS: Desoxyscirpenol, DON3G: Deoxynivalenol3-glycoside, EFSA: European Food Safety Agency, Fusarium spp.: Fusarium species, FUS-X: Fusarenone-X, MS: mass spectrometry, RP(U)HPLC: reverse phase (ultra) high performance liquid chromatography, SDS: Sodiumdodecylsulfate, s/n: signal-to-noise-ratio, USDA: United States Data Agency, UV: ultra violet light 
Cereals have made an essential contribution to human nutrition for centuries. Wheat, in particular, is one of the most important cereals worldwide. Nowadays, with a production of 713 million tons per year wheat is, after maize and rice, the third most produced cereal worldwide (FAOSTAT, 2014). It is grown on an area of 216 million hectares globally. In the 2013/2014 season 697 million tons of wheat were consumed worldwide (USDA, 2014). Its high prominence is mainly because it is the basis for a large variety of products. By far the most important is its use in the baking industry, mainly for bread, but also for cakes, biscuits etc. In addition, breakfast cereals, pasta and alcoholic beverages, like beer, are often based on wheat and it is also used for animal feed (USDA, 2013).

However, crop losses due to fungal contamination represent a significant problem for many cereals all over the world. Especially for cereals like wheat, different toxigenic Fusarium spp. are frequently found as contaminants. A very common disease due to mould contamination in the field is Fusarium Head Blight, mainly caused by Fusarium culmorum (Parry et al., 1995). Grain colonization with these moulds causes significant quality losses due to the fungus exploiting the grains nutrient resources. Furthermore, from the consumer health safety point of view, the production of mycotoxins is a major problem. Mycotoxins frequently produced by $F$. culmorum are type B trichothecenes, such as deoxynivalenol (DON) and nivalenol (NIV), type A trichothecenes, like T-2, and zearalenone (ZON) (Llorens et al., 2006, Wagacha et al., 2007). The predominant mycotoxin is DON, as it was found in $90 \%$ of all cereal samples analysed, but it can also indicate the presence of other mycotoxins (Sobrova et al., 2010). Due to its heat stability and water solubility, it is easily transferable into processed food (Lancova et al., 2008). Consequently, 
mycotoxins are well known as a substantive health hazard in the baking and brewing industries (Scudamore et al., 2009).

However, due to the permanent and ubiquitous presence of microorganisms and fungal spores in the environment, it is not possible to avoid contamination completely. Consequently, methods for reduction and control of fungal contaminations are of major interest.

Although Fusarium spp. are field fungi, infection can also occur post-harvest if the conditions are favourable. In the USA alone the post-harvest economic loss on wheat due to fungal spoilage and mycotoxins exceeds $\$ 300$ million annually (Pitt and Hocking, 2009). Furthermore, if wet grains are harvested and not dried immediately Fusarium spp. can grow post-harvest (Champeil et al., 2004). Due to this fact it is likely that i.e. during storage, small amounts of Fusarium spp. infected grains can contaminate larger amounts of healthy grains. Consequently, the mycotoxins produced could cause a health hazard for the consumer. Additionally, the technological and nutritional quality of the grains would be reduced significantly, due to the fungal metabolism. Therefore, a small field infection has the potential to cause immense economic damage.

Thus, the aim of this study was to investigate the spread of a Fusarium culmorum infection, of minor degree of initial infection, under storage conditions generally suitable for fungal growth. Although this does not resemble industrial storage practices it allows the study of the interactions of the fungus with the grains. Therefore, the behaviour of the fungus was characterised, regarding the development of biomass and the production of mycotoxins. Analysis of the grain ultrastructure was used to visibly illustrate the changes occurring to all important 
components due to the infection. Further information about the pathway of fungal infection was obtained by determining selected enzymatic activities. Finally, the fungal impact on major grain quality parameters, such as starch content and storage proteins was evaluated to estimate the reduction of marketability, leading to economic losses. Hereby, the results of this study provide essential information for the understanding of fungal proliferation during storage, which is of great interest to cereal science and industry.

\section{MATERIALS AND METHODS}

\subsection{Materials}

Commercial hard winter wheat (Triticum aestivum), harvested in 2013, was supplied by Doves Farm Foods Ltd. (Hungerford, UK). Wheat grains were stored in barrels under cool conditions $\left(<15^{\circ} \mathrm{C}\right)$ and were aerated regularly.

Fusarium culmorum TMW 4.2043 originally isolated from brewing barley was provided by the culture collection of Lehrstuhl für Technische Mikrobiologie, TUMünchen Weihenstephan.

All reagents used in the following analysis were at least analytical grade.

\subsection{Grain surface disinfection}

The grains were disinfected according to the method described by Oliveira et al., (2012b). Briefly, grain portions of $600 \mathrm{~g}$ were disinfected in $4 \mathrm{~L} 10 \%(\mathrm{w} / \mathrm{v})$ hydrogen peroxide $\left(\mathrm{H}_{2} \mathrm{O}_{2}\right)$ solution for 10 min with continuous stirring. Subsequently, the grains were washed for $5 \mathrm{~min}$ in $4 \mathrm{~L}$ distilled water. This procedure was repeated once, but with only 5 min of disinfection. Immediately, the grains were moved to sterile plastic boxes and dried at room temperature for $24 \mathrm{~h}$ under vertical sterile laminar flow. 
116 Finally, the grains were exposed to ultraviolet light (10 $\mathrm{min}$ ) and collected aseptically

117 for further use.

2.3 Preparation of fungal spore suspension and grain infection

The spore solution of Fusarium culmorum was prepared according to the method described by Oliveira et al., (2012b). Briefly, fungus was cultivated at $25^{\circ} \mathrm{C}$ for 5 days on potato-dextrose-agar (PDA) plates. After cultivation six small fragments of inoculated PDA were transferred to $800 \mathrm{~mL}$ synthetic nutrient-poor bouillon (Nierenberg, 1976). Fungal suspensions were kept at room temperature under continuous stirring to induce spore production and filtered through $30 \mu \mathrm{m}$ filter paper. The concentration of spores was determined to be $10^{5}$ spores $/ \mathrm{mL}$, using a haemocytometer.

Infected wheat grains were prepared using the following procedure. Disinfected wheat grains were mixed with $2 \%(\mathrm{v} / \mathrm{w})$ sterile filtered spore suspension of $F$. culmorum. Subsequently, grains were incubated for 10 days at $25^{\circ} \mathrm{C}$ with $75 \%$ relative humidity to allow fungal growth. The infected grains produced were defined as $100 \%$ infected. The infected grains were homogenised and analysed for moisture. Uncontaminated wheat was incubated in the same way and used as a negative control.

\subsection{Mixing and storage trials}

Infected and disinfected grains were mixed to samples of $4.5 \mathrm{~kg}$ (dry matter) with specific infection levels of $0,5,10$ and $20 \%$ and stored in model systems under conditions generally suitable for fungal growth. Each mixture and the control sample was divided into nine portions and filled into sterile plastic bags. Every bag was sealed and perforated by two pipette tips with barrier filter to allow gas exchange. 
140 The bags were stored for 6 weeks at room temperature. After 0, 3 and 6 weeks, 3 141 portions of each sample were taken, milled to a whole grain flour (particle size < $1420.5 \mathrm{~mm})$, homogenised and stored at $-20^{\circ} \mathrm{C}$ until further use.

2.5 Determination of ergosterol

144 Ergosterol content (free and ester bound) was determined using the method of Jedličkova et al. (2008) with the following modifications. The RPHPLC column used was a Nova-Pak $\mathrm{C}_{18}(300 \times 3.9 \mathrm{~mm}, 4 \mu \mathrm{m})$. Peak-identity was verified using the UVspectra recorded by the DAD. The limit of detection (LOD) and the limit of quantification (LOQ) were determined from the signal/noise $(\mathrm{s} / \mathrm{n})$ ratio. The LOD was set for $s / n$ of $3: 1$ and the LOQ was set for $s / n$ of 10:1. For calibration, ergosterol standards between 1.0 and $200 \mu \mathrm{g} / \mathrm{mL}$ in methanol were prepared and analysed. The recovery was determined by spiking an ergosterol free sample with a standard solution and found to be $95 \pm 1 \%$.

\subsection{Mycotoxin analysis}

The analysis of mycotoxins was carried out by UHPLC-MS/MS according to the method of DeColli et al. (2014). In brief, $2 \mathrm{~g}$ milled, homogenised sample was extracted by shaking by hand in the presence of $10 \mathrm{~mL}$ acetic acid $(0.1 \%, \mathrm{v} / \mathrm{v})$ for 1 min. Subsequently, $10 \mathrm{~mL}$ of acetonitrile was added and again shaken for $1 \mathrm{~min}$. Magnesium sulphate $(4 \mathrm{~g})$ and sodium chloride $(1 \mathrm{~g})$ were subsequently added to the tubes and they were shaken for $1 \mathrm{~min}$. Samples were centrifuged (3,500rpm, 10min) and $2.5 \mathrm{~mL}$ of the resulting supernatants was transferred into $15 \mathrm{~mL}$ polypropylene centrifuge tubes, which were evaporated to dryness under nitrogen at $40^{\circ} \mathrm{C}$. The residues were resuspended in $0.2 \mathrm{~mL}$ of a water/methanol mixture $(90 / 10, \mathrm{v} / \mathrm{v})$, and filtered through a $0.2 \mu \mathrm{m}$ filter, before $2.5 \mu \mathrm{L}$ was injected into the UHPLC-MS/MS system. The separation was carried out with a Waters Binary Acquity ${ }^{\mathrm{TM}}$ UHPLC 
165 System, using an Acquity $\mathrm{BEH}^{\circledR} \mathrm{C}_{18}(100 \times 2.1 \mathrm{~mm}, 1.7 \mu \mathrm{m})$ column at $40{ }^{\circ} \mathrm{C}$. The

mobile phase consisted of A) $5 \mathrm{mM}$ ammonium acetate in water/methanol $(90: 10, \mathrm{v} / \mathrm{v})$ and B) $5 \mathrm{mM}$ ammonium acetate $+0.1 \%$ acetic acid in methanol. The gradient used was $0-4 \min , 100 \% A ; 4-10 \min 10 \% A, 90 \%$ B; $10-12 \min 100 \% A$. The flow rate was $0.4 \mathrm{~mL} / \mathrm{min}$ and the run time $12 \mathrm{~min}$. Detection was carried out using a Water Quattro Premier $X E^{T M}$ with ESI interface. The LOD and LOQ were determined from the $s / n$ ratios. The LOD was set for $s / n$ of $3: 1$ and the $L O Q$ was set for $s / n$ of $10: 1$. Standard curves for each mycotoxin analyzed were obtained by matrix calibration. The samples were measured as single determinations.

\subsection{Grain ultrastructure}

Examination of the grain ultrastructure was carried out using a JEOL scanning electron microscope type 5510 (JEOL, Tokyo, Japan) as described by Oliveira et al. (2012b). Briefly, freeze-dried grains were manually cut in several cross sections ( $n$ > 15). These fragments were mounted onto aluminium stubs with carbon double surface adhesive. After covering the samples with a $7 \mathrm{~nm}$ gold layer, using a Gold sputter coater (BIO-RAD Polaron Division, SEM coating system, England), samples were placed in the microscope and examined under constantly accelerating voltage of $5 \mathrm{kV}$.

\subsection{Grain quality parameters}

The stored grains were characterised by determining the moisture content and the $\mathrm{pH}$-value, using the standard AACC methods 44-15A (moisture) and 02-52.01 $(\mathrm{pH})$. Furthermore, the water activity on the surface of the grains was determined with the HygroLabC1 water activity meter (Rotronic Messgeräte, Ettlingen, Germany), according to the instructions given in the manual (Rotronic, 2014). Changes in enzymatic activities due to the fungal infection were evaluated by determination of $\alpha$ - 
amylase activity, $\beta$-glucanase activity, endo-1,4- $\beta$-xylanase activity (Megazyme Int., Ireland), total protease activity, using a haemoglobin standard (Brijs et al., 2002), lipase activity by the copper soap assay (Rose and Pike, 2006) and $\beta$-amylase activity using the method described by Hyun et al. (1985), (Table 3).

Proteins were sequentially extracted, following the method described by Oliveira et al., (2013). Freeze dried grains were milled to a fine flour. Each extraction was carried out in duplicate. Protein concentrations of the joined extracts were determined by the protein dye binding method of Bradford (Bradford, 1976), using bovine serum albumin as a standard.

The extracts obtained from the Osborne fractionation were analysed further by SDS gel electrophoresis, using the Bioanalyzer 2100 (Agilent Technologies, Palo Alto, CA), according to the instructions given in the manual (Agilent, 2014) for the Protein80+ chip. The analysis was carried out in a molecular weight range of $4.5-$ $95 \mathrm{kDa}$. The results are shown (Figure 2) in an electrophoretogram (graphic representation of protein peaks and intensities), where the peak heights equal the intensity of bands in the gel.

The total amount of starch was determined by the amyloglucosidase / a-amylase method (Megazyme Int, Ireland). Selected saccharides were determined as free sugars according to the method described by Wolter et al. (2014), using HPLC system with refractive index detector. Appropriate sugar standards, representing degradation of starch and fibres, were used to identify and quantify the concentration in the samples in correlation to the standard peak area. 
213 Samples were stored in triplicate and after sampling homogenised. All analyses were run in triplicate, unless otherwise stated. Statistical analysis was performed using Minitab 17 software. Data were checked for outliers (Grubb's test) and evaluation of significant differences was performed using one-way analysis of variances (ANOVA). All differences were considered significant at $\mathrm{P}<0.05$. Where F-values were significant, pairwise comparisons were carried out with the help of Tuckey Post Hoc test to describe the statistical significance between the infected and uninfected grains over time of storage.

\section{RESULTS AND DISCUSSION}

222

For this study Fusarium culmorum was chosen as an indicator strain, as it is the main reason of grain spoilage, particularly in Central and Western Europe (Parry et al., 1995).

Because of its oxidising power, $\mathrm{H}_{2} \mathrm{O}_{2}$ is known to have bactericidal and bacteriostatic activity. Furthermore it has the GRAS (Generally Regarded As Safe) status (Juven and Piersen, 1996). Due to the short contact time with the grains and the immediate washing after disinfection it has just minor effects on the wheat quality in terms of germinating ability and technological performance. Furthermore, hydrogen peroxide breaks into water and oxygen, leaving no residue.

After the artificial infection, all samples showed a water activity of $>0.80$ and a $\mathrm{pH}$ between 6.5 and 6.6 (data not shown). Therefore the storage conditions were found to be generally suitable for fungal growth and allowed the investigation of the spread of $F$. culmorum in wheat during the storage period. Consequently, it was possible to study the fungal impact on important grain quality criteria. 
237 To evaluate the spread of the infection during storage, the fungal biomass was determined by quantification of the total ergosterol content. The results of this determination are shown in Table 1.

240 For all natural and 0\% infected samples (week 0, 3 and 6) no ergosterol could be determined, as the signals obtained were below the LOD. Consequently, no measurable fungal growth occurred in these samples during storage.

243 In all the infected samples a significant increase in ergosterol contents was found during storage. At least a six fold increase (20\% infected sample) was observed within the 6 week storage time. The highest rise was found for the $5 \%$ infected sample with levels ranging from $<$ LOD $(<0.75 \mathrm{mg} / \mathrm{kg})$ up to $44.2 \pm 1.3 \mathrm{mg} / \mathrm{kg}$. This shows how fast even a minor level of initial infection can turn into a substantial contamination. Furthermore, after just 3 weeks of storage no significant difference between the three infection levels was found anymore $(p<0.05)$. After 6 weeks, the $5 \%$ and $10 \%$ infected samples showed significantly higher ergosterol contents than the $20 \%$ infected sample $(p<0.05)$. This result can be explained by the competition of

252 the fungus for nutrients, which was at the beginning of the storage in the $20 \%$ 253 infected sample the highest. Furthermore, this sample had the highest moisture 254 content. Consequently, the air-filled porosity of the grains was different. Therefore, it 255 is possible that a "water-logged" situation appeared. This leads to reduced oxygen availability and increased $\mathrm{CO}_{2}$ contents, inhibiting the growth of the fungus (Atalla et al., 2003). 
259 The production of mycotoxins is related to the fungal growth (Oliveira et al., 2012b). Accordingly, qualitative and quantitative analysis of characteristic Fusarium toxins was carried out. Table 1 shows that the mycotoxins DON, DON3G and 3-ADON were found in all - and ZON in some of the infected samples. However, no detectable amounts of T-2, HT-2, DAS, FUS-X or NIV were found in any of the samples analysed. Regarding DON and its metabolites the mycotoxin contents at the start of the storage strongly correlated with the degree of infection. The $5 \%$ infected sample showed the lowest and the $20 \%$ infected sample, the highest amounts of DON, DON3G and 3ADON. However, in contrast to the ergosterol concentrations, the levels of DON and its metabolites were strongly decreasing during storage. The $20 \%$ infected sample presented the highest decrease within the 6 weeks (50\%). For the DON3G an even higher loss of up to $75 \%$ was detected ( $20 \%$ infected sample). The ZON concentrations presented only minor changes during storage and were found to be widely independent from the infection level.

This result indicates that mycotoxins, especially DON, DON3G and 3ADON, but also ZON are mainly produced during the initial phase of colonisation, but not in the ongoing spread of the infection. The reasoning behind this result is the key role which DON and its metabolites play for the initial infection by supressing the pathogendefence mechanisms of the grain (Hestbjerg et al., 2002). However, later on when the fungus had established itself post the initial infection, it was no longer forced to produce mycotoxins. This correlates well with previous studies which showed that, Fusarium spp. during malting produce the most mycotoxins during the kilning stage, when the fungus was particularly exposed to environmental stress (Oliveira et al., 2012b). Since this investigation applied no antifungal agents and the storage conditions were chosen to be very suitable for fungal growth, this environmental 
stress forcing $F$. culmorum to produce mycotoxins was missing. Thus, the energy was used to produce biomass instead, as analysed by the increasing ergosterol contents. However, one might expect that due to the lack of mycotoxins production, the amounts determined would not change during storage. But in fact, the amounts of DON, DON3G and 3ADON decreased considerably. This could be due to various reasons. Atalla et al. (2003) reported decreasing DON contents (produced by Aspergillus spp.) in wheat during storage and concluded that reabsorption by the fungus had occurred. Another explanation would be that the DON was metabolised by the grain or the fungus itself. Furthermore, DON3G and 3ADON are known to be highly unstable at room temperature. Consequently, a decay of these compounds was possible.

However, after at least 3 weeks of storage, all samples were below the highest permitted amounts for DON $(1250 \mu \mathrm{g} / \mathrm{kg})$ and ZON $(100 \mu \mathrm{g} / \mathrm{kg})$ for unprocessed wholemeal flour, could still cause a health hazard. The USDA (2014) recommends a daily intake of wholegrain for women of at least 6 ounce equivalents, which corresponds to $170 \mathrm{~g}$. The infected sample with the lowest amount of DON detected was the $5 \%$ infected sample after 6 weeks. It was found to contain $446 \mu \mathrm{g} / \mathrm{kg} \mathrm{DON}$. For the recommended daily consumption of wholegrain wheat this means a DON intake of $76 \mu \mathrm{g}$. The EFSA (2003) released a tolerable daily intake (TDI) for different mycotoxins such as DON (1.0 $\mu \mathrm{g} / \mathrm{kg}$ body weight) and ZON $(0.2 \mu \mathrm{g} / \mathrm{kg}$ body weight, provisional). Even the sample with the lowest amount of DON analysed in this study would cause a daily intake of $75.8 \mu \mathrm{g}$ for women, which is very likely already enough to exceed the TDI. The same "worst case" calculation for the ZON intake leads to a similar result. Considering that this example applies to the sample with the lowest 
amount of mycotoxins detected, the other samples analysed would constitute an even bigger health hazard. Furthermore, it is noteworthy that wholegrain products are not the only source of mycotoxins in human nutrition and that the samples analysed in this study were artificially infected and intentionally stored under poor conditions to promote fungal growth and mycotoxin production. Therefore, they are likely to present higher mycotoxin contents than natural samples would do.

Finally, it can be concluded that even without an accumulation of mycotoxins during storage a serious health hazard could be caused by the wholegrain flours obtained from any of the infected samples presented here.

\subsection{Grain ultrastructure}

In order to obtain information about the fungal impact on the grain ultrastructure and to illustrate the pathway of fungal infection, scanning electron microscopy (SEM) was performed. As the surface disinfection and the level of initial infection had no visible impact on the grains structural characteristics, only images of the natural and $20 \%$ infected samples are shown in Figure 1.

Figures $1 \mathrm{~A}$ and $1 \mathrm{~B}$ show the natural sample, week 0 and 6 , respectively. The different husk layers are well visible in both samples. However, on the outer layers of the sample in image $1 \mathrm{~A}$ some small fungal hyphae can be seen. Since this sample was neither infected nor disinfected, these hyphae are most likely due to natural field contamination. However, as no substantial amounts of ergosterol (indicating fungal growth) and mycotoxins were found in this sample, the occurrence of these few hyphae is not representative, and likely represents a low level of natural contamination which would present negligible effects on grain quality and consumer health. Following the husk, the endosperm of the grain occurs. In the endosperm of 
333 both samples many starch granules are visible, embedded in a dense protein network. The $20 \%$ infected sample after week 0 and 6 is shown in Figures $1 \mathrm{C}$ and $1 \mathrm{D}$, respectively. In $1 \mathrm{C}$, the different husk layers are well visible. Since there are no fungal hyphae present, the damage of the husk (in form of cracks) is due to the manual cutting of the kernel. This is in contrast with sample 1D. The outside of this sample is visibly overgrown with fungal hyphae. The husk appears to be penetrated and severely damaged by the fungus. In addition, it is clearly deformed and no individual layers can be differentiated anymore. Furthermore, fungal hyphae were also found in the starchy endosperm. While the endosperm in 1C looks quite similar to the natural sample, in 1D even in the areas without fungal hyphae, it shows a much less dense protein network, indicating proteolytic activity. The results obtained in this study correlate well with the findings of Tucker and Talbot (2001) where the fungal infection starts with adhesion of macro conidia on the grain surface. This is followed by emergence of the germ tube. Immediately, release of various plant pathogen signals, enzymes and hormones follows. Directly afterwards, the hyphal network develops and host penetration occurs. Furthermore, the testa was found to be a strong barrier, which the fungus penetrated only after 3 weeks of storage. These outcomes are in good correlation with the findings of Oliveira et al. (2012b) on barley, infected with $F$. culmorum. They concluded that this is due to the high concentration of phenolic acids in the testa, which can act as antifungal agents.

The endosperm of the natural sample after week 0 and 6 is shown in Figures $1 \mathrm{E}$ and $1 \mathrm{~F}$, respectively. Both images show small and big starch granules embedded in a dense protein matrix. The starch granules appear in a smooth and regular shape and no signs of degradation are visible. Furthermore, no fungal hyphae are noticeable. The endosperm of the $20 \%$ infected samples after week 0 and 6 is shown in Figures 
$3581 \mathrm{G}$ and $1 \mathrm{H}$, respectively. In Figure $1 \mathrm{G}$ the protein matrix appears to be much less dense, indicating degradation and leading to very exposed starch granules. However, no fungal hyphae were found in this sample and the small and big starch granules show no signs of degradation. In contrast to this, there are hardly any small starch granules visible in image $1 \mathrm{H}$. Also, the big starch granules present obvious signs of degradation in the form of holes. Furthermore, the protein matrix appears to be widely degraded and replaced by fungal hyphae. These images show that just 6 weeks of storage were enough to cause severe damage in the infected samples. This also correlates well with the results reported by Jackowiak et al. (2005). Furthermore, these results indicate the production, or at least activation, of hydrolytic enzymes by the fungus, leading to the degradation of starch and proteins. Consequently, it can be expected that the grains infected with $F$. culmorum show a significant quality loss. To analyse this further, an investigation into the fungal effects on the grain carbohydrates and proteins was performed.

The visible degradation of the starch granules during the storage due to the fungal infection was also quantified, as this parameter has a major impact on the wheat quality, in terms of technological applications. Accordingly, starch and selected free saccharides were quantified. The results are summarised in Table 2.

The starch content of the uninfected samples was found to be between $63 \pm 1$ and $65 \pm 1 \%$, which is within the normal range for wheat of $63-72 \%$ (Borght et al., 2005). Furthermore, no significant changes occurred during the storage. Also the infected samples week 0 were found to contain $63 \pm 1-65 \pm 1 \%$ starch. However, in contrast to the healthy grains they presented a substantial loss of 10 to $12 \%$ starch during 
storage. Consequently, the starch contents of these samples after 6 weeks were between $52 \pm 1$ and $54 \pm 1 \%$, which means a substantial loss in grain quality. Furthermore, it has to be mentioned that at the end of the storage no noteworthy differences between the starch contents of the three initial infection levels were found, indicating that the starch degradation occurs widely independent from the level of initial infection.

In good correlation to this were the levels of free maltotriose, maltose and glucose measured. None of those saccharides were found in the uninfected samples or the infected samples at week 0 . However, substantial amounts were measured in the infected samples after 3 and 6 weeks. Consequently, it can be concluded that these saccharides were released from starch and fibres due to their degradation by fungal enzymes. Additionally, it is evident that the highest amounts of maltotriose and maltose occurred after 3 weeks, whereas the highest amount of glucose was found after 6 weeks. This is caused by the further degradation of the oligosaccharides to glucose, which is used as a nutrient by $F$. culmorum. The analysis of free raffinose and sucrose revealed that they occur naturally in wheat, as they were found in the uninfected samples. Although the infected samples also showed noteworthy amounts in week 0 , after 3 (sucrose) and 6 (raffinose) weeks they could not be detected anymore. This, again, indicates degradation by fungal enzymes to monomeric glucose, fructose and galactose, which are consumed by the fungus. In correlation with this, free fructose was found in the infected samples after 3 and 6 weeks of storage. However, the amounts of monosaccharides present were relatively low compared to the level of degradation of the di- and trisaccharides apparent. This proves that these monosaccharides were consumed as nutrients by the fungus. Generally, the results of the carbohydrate quantification, with the 
reduction in poly- and oligosaccharides and the release of monosaccharides, shows a significant loss in grain quality, correlating well with the structural deterioration, visible on the SEM images.

\subsection{Fungal impact on Protein fractions}

Aiming to characterise the changes occurring to the proteins, the Osborne fractions of all samples were quantified with the Bradford (1976) dye binding method (Table 2). As expected, no substantial changes were detected in the uninfected samples during storage. For the albumin fraction of the infected samples, increasing amounts of extractable proteins were determined during the storage $(p<0.05)$. Since this fraction mainly contains metabolically active proteins, the increase indicates a gain in enzymatic activities, as could be expected due to the degradation of carbohydrates shown above. In contrast to this, the globulin, prolamin and glutelin fractions of the infected samples showed no substantial differences in soluble protein contents compared to the uninfected controls. However, the degradation of proteins also increases their solubility, leading to a better extractability and so masking the consumption of some degradation products by the fungus.

From the grain quality point of view the storage proteins are of major interest, as they contain the proteins which form the gluten network. Since quality and quantity are the most important quality parameters for wheat flour, the prolamin and glutelin fractions were further characterised using gel electrophoresis. These results are shown in Figure 2. In both fractions none of the uninfected samples showed any significant differences during storage (data not shown). The electrophoretogram of the prolamin fraction (Figure 2A) shows 15 distinguishable peaks, excluding the internal markers at 1.6 and $95 \mathrm{kDa}$. A significant decrease was found for five of the 
431 protein peaks $(1,3,9,11,12)$ due to the fungal infection. On the other hand, there 432 were several peaks in the infected sample found to have an increased intensity at the end of the storage $(2,4,5,6,7,13,15)$. Most likely these peaks represent the degradation products of prolamins of higher molecular weight. The prolamin fraction of wheat is essential for the formation of the gluten network. Consequently, its degradation by the fungus leads to a significant loss in grain quality. The electrophoretogram of the glutelin fraction (Figure 2B) contains, besides of the internal standards at $1.6,3.5$ and $95 \mathrm{kDa}, 8$ distinguishable peaks for the natural sample. The infected sample after 6 weeks shows a total breakdown of the proteins in the size range analysed, as there were no peaks distinguishable anymore. The contrast to the results obtained by Bradford, where no changes in the glutelin content were found, is caused by the fact that the Bioanalyzer measured just between 4.5 and $95 \mathrm{kDa}$, whereas Bradford detects all proteins that dissolve. Furthermore, degradation of the glutelins improves their solubility. In similarity to the prolamins breakdown, the degradation of the glutelins causes a quality loss as they are essential for the gluten network as well. Generally, the electrophoretic results confirmed the visible degradation of the protein matrix in the endosperm, as seen on the SEM images.

3.6 Fungal impact on enzymatic activities

In order to obtain further information about the pathway of fungal infection, regarding the penetration into the endosperm and hydrolysis of proteins and polysaccharides (as quantifies and visible on the SEM images), the activity of selected enzymes was determined. The results of these enzymatic determinations are summarised in Table 3. 
Lipases and xylanases are primarily tools of the fungus to overcome the physical barriers of the grain. The xylanase is, due to degradation of arabinoxylan, known as one of the major cell wall degrading enzymes for wheat. Lipases, on the other hand, are mainly released to degrade the cuticle, which is the outer protective barrier of wheat grains. Regarding the activity of lipases, the infected samples showed, particularly towards the end of storage, between weeks 3 and 6 , a substantial increase. Values of the 10 and $20 \%$ infected samples were found with a 4 fold increase. While at the beginning of the storage no significant differences were detected between the three infection levels, after 6 weeks the lipase activity was found to be in direct correlation with the initial infection level. Thus, the expression of lipase, which degrades the cuticle, occurred basically during the second half of storage. Consequently, the increase in lipase activity can be seen as an indication for the on-going infection process. It also shows that a higher level of infection leads to a faster penetration into deeper grain layers. A similar development was found for the xylanase activity, except that the activity was widely independent from the level of initial infection, even after 6 weeks. Thus, increased xylanase activity also indicates the on-going infection due to penetration into the endosperm. In the uninfected controls, activities of both enzymes remained consistently low, without significant changes $(p<0.05)$, during the whole storage period.

These results also correlate well with the observation from the SEM images, showing that the fungus first overgrows the surface, before penetrating into deeper layers. The penetration into the kernel is of major importance to the fungus and the on-going infection process, as it provides access to the endosperm, which is a source of nutrients. In addition, it is noteworthy that free arabinose was also detected (Table 2), which is a degradation product of the arabinoxylan of the cell walls. As substantial 
amounts of free arabinose were only found in the infected samples after 6 weeks, the result correlates with the xylanase activity, showing that the fungus penetrates into the endosperm after a few weeks of storage. Additionally, the degradation of the cell walls also leads to a loss in fibre. This reduces the nutritional value of the whole meal flour obtained from these grains and also effects technological quality parameters, such as water binding during dough preparation.

However, from the technological point of view the protein and starch degrading enzymes have an even higher impact on the grain quality. Analysis of these enzymes revealed an increase in total proteolytic, $\alpha$-amylase and $\beta$-amylase activity for all three infection levels during the storage, but not for the uninfected samples. This is in good correlation with the degradation of starch and storage proteins, as seen on the SEM images and quantified above. Thus, it can be concluded that this increased activity is caused by $F$. culmorum, in order to obtain essential nutrients in form of amino acids and glucose. Also the $\beta$-glucanase activity was found to increase during the storage of the infected samples. The degradation of glucans such as cellulose provides glucose for the fungus. Consequently, the increase of activity in the infected but not in the uninfected samples correlates with the aim of the fungus to release nutrients, which provide energy for growth. It is noteworthy that no significant differences in the enzymatic activities between the different levels of initial infection could be found after 6 weeks. Accordingly, it shows once more that a $5 \%$ level of initial infection can cause similar damage as a $20 \%$ initial infection level. Since all these enzymes cause a quality loss due to degradation of either nutrients or cells, the grain quality is substantially reduced, widely independent of the initial infection level. However, the results cannot show if the enzymes are produced by the 
fungus or the grain and activated due to the stress of the fungal infection. However, their activity is related to the fungal infection.

\section{CONCLUSION}

The aim of this study was to investigate the spread of a $F$. culmorum infection in stored wheat and its impact on the grain quality. The increasing amounts of ergosterol detected during the storage indicates a rapid increase of fungal biomass under the chosen storage conditions. Firstly, a substantial quality loss of the grains was shown by the mycotoxins detected, which are likely to cause a health risk to a potential consumer. Furthermore, quality loss from the technological point of view was shown, mainly due to degradation of polysaccharides, such as starch, and storage proteins. After storage, none of the infected samples fulfilled the quality requirements for wheat flour. Thus, the need to develop efficient decontamination methods for cereals which can be applied during storage, without affecting the grain quality, has clearly been demonstrated. The contribution of enzymes, produced exogenously or induced in grains by fungal stress, was illustrated but warrants further study to fully understand the pathways of fungal infection. In addition, the fungal impact on gluten quality and the resulting dough and bread would be of further interest.

\section{ACKNOWLEDGEMENTS}

Funding for Marcus Schmidt was received through the Irish Government under the National Development Plan 2007 - 2013 through the research program FIRM/RSF/CoFoRD. This research was also partly funded by Irish Department of Agriculture, Food and the Marine. 
530 AACC International. Approved Methods of Analysis, 11th Ed. Method 44-15A.

531 Moisture content - air oven method. Approved November 3, 1999. AACC

532 International, St. Paul, MN, U.S.A. http://dx.doi.org/10.1094/AACCIntMethod-44-15A

533 AACC International. Approved Methods of Analysis, 11th Ed. Method 02-52.01.

534 Hydrogen-lon Activity $(\mathrm{pH})$ - Electrometric Method. Approved November 3, 1999.

535 AACC International, St. Paul, MN, U.S.A. http://dx.doi.org/10.1094/AACCIntMethod$536 \quad 02-52.01$

537 Atalla, M.M., Hassanein, N.M., El-Beih, A.A., Youssef, Y.A.-G., 2003. Mycotoxin 538 production in wheat grains by different Aspergilli in relation to different relative 539 humidities and storage periods. Nahrung/Food, 47 (1): $6-10$

540 Borght, A., Goesert, H., Veraverbeke, W.S., Delcour, J.A., 2005. Fractionation of 541 wheat and wheat flour into starch and gluten: overview of the main processes and 542 the factors involved. Journal of Cereal Science 41: 221-237

543 Bradford, M.M., 1976. A rapid and sensitive method for the quantitation of microgram 544 quantities of protein utilizing the principle of protein-dye binding. Analytical 545 Biochemistry, 72: 248-254

546 Brijs, K., Trogh, I., Jones, B.L., Delcour, J.A., 2002. Proteolytic Enzymes in 547 Germinating Rye Grains. Cereal Chemestry, 79 (3): 423 - 428

548 Champeil, A., Dore, T., Fourbet, J., 2004. Fusarium head blight: epidemiological 549 origin of the effects of cultural practices on head blight attacks and the production of 550 mycotoxins by Fusarium in wheat grains. Plant Science, 166: 1389-1415 
551 DeColli, L., Elliott, C., Danaher, M., 2014. Development of a multi-residue method for

552 the analysis of mycotoxins, including masked mycotoxins, in cereal-based food by 553 UHPLC-MS/MS. 43 ${ }^{\text {rd }}$ Annual Food Research Conference, 10-11 ${ }^{\text {th }}$ December $2014-$ 554 O`Brien Centre UCD.

555 EFSA, 2003. COLLECTION OF OCCURRENCE DATA OF FUSARIUM TOXINS IN FOOD AND ASSESSMENT OF DIETARY INTAKE BY THE POPULATION OF EU MEMBER STATES. Directorate-General Health and Customer Protection, Task

559 EFSA, 2006. Commission Regulation (EC) No 1881/2006 of 19 December 2006 setting maximum levels for certain contaminants in foodstuffs. European Food Safety Authority.

FAOSTAT, 2014. Annual wheat production 2000 - 2013 on average. Food and Agriculture Organization of the United Nations, Rome

Hestbjerg, H., Felding, G., Elmholt, S., 2002. Fusarium culmorum infection of barley seelings: Correlation between aggressiveness and deoxynivalenol content. Journal of Phytopathology, 150: $308-316$

567 Hyun, H.H., Zeikus, J.G., 1985. General Biochemical Characterisation of 568 Thermostable Extracellular $\beta$-Amylase from Clostridium thermosulfurogenes. Applied and Environmental Microbiology, 49 (5): 1162 - 1167

570 Jackowiak, H., Packa, D., Wiwart, M., Perkowski, J., 2005. Scanning electron 571 microscopy of Fusarium damaged kernels of spring wheat. International Journal of

572 Food Microbiology, 98 (2): 113 - 123 
573 Jedličkova, L., Gadas, D., Havlova, P., Havel, J., 2008. Determination of Ergosterol 574 Levels in Barley and Malt Varieties in the Czech Republic via HPLC. Journal of

575 Agricultural and Food Chemistry, 56: 4092 - 4095

576 Juven, B.J., Pierson, M.D., 1996. Antibacterial Effects of Hydrogen Peroxide and 577 Methods for Its Detection and Quantitation. Journal of Food protection, 11: 1153 578 1247

Lancova, K., Hajslova, J., Kostelanska, M., Kohoutkova, J., Nedelnik, J., Moravcova, H., Vanova, M., 2008. Fate of trichothecene mycotoxins during the processing: Milling and baking. Food Additives and Contaminants, 25(5): 650-659

Llorens, A., Hinojo, M.J., Mateo, R., Gonzalez-Jaen, M.T., Valle-Algarra, F.M., Logrieco, A., Jimenez, M., 2006. Characterization of Fusarium spp. isolates by PCRRFLP analysis of the intergenic spacer region of the rRNA gene (rDNA). International Journal of Food Microbiology, 106: 287-306

Nirenberg, H., 1976. Untersuchungen uber die morphologische und biologische Differenzierung in der Fusarium-Sektion Liseola. Mitteldeutsche Biologische Bundesanstalt fuer Land- und Forstwirtschaft Berlin-Dahlem 169, 1-117

589 Oliveira, P.M., Mauch, A., Jacob, F., Waters, D.M., Arendt, E.K., 2012b. 590 Fundamental study on the influence of Fusarium infection on quality and 591 ultrastructure of barley malt. International Journal of Food Microbiology 156: 32-43

592 Oliveira, P.M., Waters, D. M., Arendt, E. K., 2013. The impact of Fusarium culmorum 593 infection on the protein fractions of raw barley and malted grains. Journal of Applied 594 Microbiology and Biotechnology, 97: 2053 - 2065 
595 Parry, D. W., Jenkinson, P., McLeod, L., 1995. Fusarium ear blight (scab) in small 596 grain cereals-a review. Plant Pathology, 44: 207-238

597 Pitt, J., Hocking, A.D., 2009. Fungi and Food Spoilage. (3 ${ }^{\text {rd }}$ ed) Springer Verlag

598 Rose, D.J., Pike, O.A., 2006. A simple method to measure lipase activity in wheat 599 and wheat bran as an estimation of storage quality. Journal of American Oil 600 Chemistry Society, $83(5): 415-419$

601 Scudamore, K.A., Hazel, C.M., Patel, S., Scriven, F., 2009. Deoxynivalenol and 602 other Fusarium mycotoxins in bread, cake and biscuits produced from UK-grown 603 wheat under commercial and pilot scale conditions. Food Additives and 604 Contaminants: Part A, 26 (8): $1191-1198$

Sobrova, P., Adam, V., Vasatkova, A., Belkova, M., Zeman, L., Kizek, R., 2010 606 Deoxynivalenol and its toxicity. Interdisciplinary Toxicology, 3(3): 94-99 Tucker, S.L., Talbot, N.J., 2001. Surface attachment and pre-penetration stage 608 development by plant pathogenic fungi. Annual Review of Phytopathology, 39: 385417

610

USDA, 2013. Agricultural Marketing Service: Grain and Oilseed Shipment Sizes and Distances Hauled by Rail. United States Department of Agriculture. Foreign Agricultural Service.

USDA, 2014. World Agricultural Production: World Markets and Trade Arquives. United States Department of Agriculture. Foreign Agricultural Service.

615 Wagacha, J.M., Muthomi, J.W., 2007. Fusarium culmorum: Infection process, 616 mechanisms of mycotoxin production and their role in pathogenesis in wheat. Crop 617 Protection, $26(7): 877-885$ 
619 Wolter, A., Hager, A.-S., Zannini, E., Czerny, M., Arendt, E.K., 2014. Impact of 620 sourdough fermented with Lactobacillus plantarum FST 1.7 on baking and sensory 621 properties of gluten-free breads. European Food Research and Technology, 239 (1): $622 \quad 1-12$ 
Table 1: Ergosterol and mycotoxin contents of wheat samples

\begin{tabular}{|c|c|c|c|c|c|c|c|c|c|c|}
\hline $\begin{array}{l}\text { sample / weeks of } \\
\text { storage }\end{array}$ & ergosterol mg/kg & NIV $\mu g / k g$ & $\begin{array}{l}\text { DON } \\
\mu g / k g\end{array}$ & $\begin{array}{l}\text { DON3G } \\
\mu \mathrm{g} / \mathrm{kg}\end{array}$ & $\begin{array}{l}\text { 3-ADON } \\
\mu \mathrm{g} / \mathrm{kg}\end{array}$ & $\begin{array}{l}\text { DAS } \\
\mu \mathrm{g} / \mathrm{kg}\end{array}$ & $\begin{array}{l}\mathrm{HT}-2 \\
\mu \mathrm{g} / \mathrm{kg}\end{array}$ & $\begin{array}{l}\mathrm{T}-2 \\
\mu \mathrm{g} / \mathrm{kg}\end{array}$ & $\begin{array}{l}\mathrm{ZON} \\
\mu \mathrm{g} / \mathrm{kg}\end{array}$ & $\begin{array}{l}\text { FUS-X } \\
\mu g / k g\end{array}$ \\
\hline natural / 0 & $<L O D$ & $<L O D$ & $<L O D$ & $<L O D$ & $<L O D$ & $<L O D$ & $<L O D$ & $<L O D$ & $<L O D$ & $<L O D$ \\
\hline natural / 3 & $<L O D$ & $<L O D$ & $<L O D$ & $<L O D$ & $<L O D$ & $<$ LOD & $<L O D$ & $<$ LOD & $<$ LOD & $<L O D$ \\
\hline natural / 6 & $<L O D$ & $<$ LOD & $<L O D$ & $<L O D$ & $<L O D$ & $<L O D$ & $<L O D$ & $<L O D$ & $<$ LOD & $<L O D$ \\
\hline $0 \%$ infected / 0 & $<L O D$ & $<L O D$ & $<L O D$ & $<L O D$ & $<L O D$ & $<L O D$ & $<L O D$ & $<L O D$ & $<L O D$ & $<$ LOD \\
\hline $0 \%$ infected / 3 & $<L O D$ & $<L O D$ & $<L O D$ & $<L O D$ & $<L O D$ & $<L O D$ & $<L O D$ & $<L O D$ & $<L O D$ & $<L O D$ \\
\hline $0 \%$ infected / 6 & $<$ LOD & $<L O D$ & $<L O D$ & $<L O D$ & $<L O D$ & $<L O D$ & $<L O D$ & $<L O D$ & $<L O D$ & $<L O D$ \\
\hline $5 \%$ infected / 0 & $<L O D$ & $<$ LOD & 719 & 119 & 15.1 & $<L O D$ & $<L O D$ & $<$ LOD & 33.3 & $<L O D$ \\
\hline $5 \%$ infected / 3 & $8.6 \pm 0.8^{a}$ & $<L O D$ & 510 & 147 & $<L O D$ & $<L O D$ & $<L O D$ & $<L O D$ & $<L O D$ & $<L O D$ \\
\hline $5 \%$ infected / 6 & $44.2 \pm 1.3^{b}$ & $<L O D$ & 446 & 73 & $<L O D$ & $<L O D$ & $<L O D$ & $<L O D$ & $<L O D$ & $<L O D$ \\
\hline $10 \%$ infected / 0 & $2.9 \pm 0.1^{c}$ & $<L O D$ & 1271 & 417 & 19.7 & $<L O D$ & $<L O D$ & $<L O D$ & 62 & $<L O D$ \\
\hline $10 \%$ infected / 3 & $10.8 \pm 0.7^{d}$ & $<L O D$ & 912 & 231 & $<L O D$ & $<L O D$ & $<L O D$ & $<L O D$ & 58 & $<L O D$ \\
\hline $10 \%$ infected / 6 & $40.4 \pm 1.3^{\mathrm{e}}$ & $<L O D$ & 953 & 160 & $<L O D$ & $<L O D$ & $<L O D$ & $<L O D$ & 70 & $<L O D$ \\
\hline $20 \%$ infected / 0 & $5.2 \pm 0.2^{\dagger}$ & $<L O D$ & 1739 & 779 & 19.6 & $<L O D$ & $<$ LOD & $<L O D$ & 70 & $<L O D$ \\
\hline $20 \%$ infected / 3 & $10.0 \pm 0.7^{d}$ & $<L O D$ & 961 & 408 & 12.7 & $<L O D$ & $<L O D$ & $<L O D$ & 25.0 & $<L O D$ \\
\hline $20 \%$ infected / 6 & $30.1 \pm 1.2^{g}$ & $<L O D$ & 937 & 210 & $<L O D$ & $<L O D$ & $<L O D$ & $<L O D$ & 78 & $<L O D$ \\
\hline $100 \%$ infected / 0 & $15.8 \pm 1.1^{\mathrm{h}}$ & $<L O D$ & 8998 & 5501 & 39.0 & $<L O D$ & $<L O D$ & $<L O D$ & 411 & $<L O D$ \\
\hline
\end{tabular}


\# Results shown are average values \pm confidence interval. Values in one column followed by the same upper case letter are not significantly different $(p<0.05)$

626

Table 2: Quantification of carbohydrates and protein fractions (obtained from Osborne fractionation) ${ }^{\#}$

\begin{tabular}{|c|c|c|c|c|c|c|c|c|c|c|c|c|c|c|c|c|c|}
\hline \multirow[b]{2}{*}{ sample / weeks of storage } & \multicolumn{10}{|c|}{ carbohydrates } & \multicolumn{7}{|c|}{ proteins } \\
\hline & $\begin{array}{l}\text { total starch } \\
\text { [\%] }\end{array}$ & $\begin{array}{l}\text { maltotri } \\
{[\mathrm{mg} / \mathrm{g}]}\end{array}$ & $\begin{array}{l}\text { raf } \\
{[\mathrm{mg} / \mathrm{g}}\end{array}$ & & $\begin{array}{l}\text { mal } \\
{[\mathrm{mg} / \mathrm{g}]}\end{array}$ & $\begin{array}{l}\text { suc } \\
{[\mathrm{mg} / \mathrm{g}]}\end{array}$ & & $\begin{array}{l}\text { glu } \\
{[\mathrm{mg} / \mathrm{g}]}\end{array}$ & $\begin{array}{l}\text { fru } \\
{[\mathrm{mg} / \mathrm{g}]}\end{array}$ & $\begin{array}{l}\text { ara } \\
{[\mathrm{mg} / \mathrm{g}]}\end{array}$ & $\begin{array}{l}\text { albumin } \\
\text { [mg/g] }\end{array}$ & & $\begin{array}{l}\text { globulir } \\
{[\mathrm{mg} / \mathrm{g}]}\end{array}$ & & $\begin{array}{l}\text { prolamin } \\
{[\mathrm{mg} / \mathrm{g}]}\end{array}$ & & $\begin{array}{l}\text { glutelins } \\
{[\mathrm{mg} / \mathrm{g}]}\end{array}$ \\
\hline natural / 0 & $65 \pm 1^{\mathrm{ab}}$ & $<$ LOD & $\begin{array}{l}5.2 \\
0.3^{\mathrm{a}}\end{array}$ & \pm & $<$ LOD & $\begin{array}{l}12.8 \\
0.3^{a}\end{array}$ & & $<$ LOD & $<$ LOD & $<$ LOD & $\begin{array}{l}11.7 \\
0.1^{a b}\end{array}$ & \pm & $\begin{array}{l}7.5 \\
0.6^{\mathrm{a}}\end{array}$ & \pm & $\begin{array}{l}13.4 \\
0.1^{\text {acf }}\end{array}$ & \pm & $\begin{array}{l}6.3 \pm \\
0.3^{a b d}\end{array}$ \\
\hline natural / 3 & $64 \pm 1^{\mathrm{abg}}$ & $<$ LOD & $\begin{array}{l}8.4 \\
0.1^{b}\end{array}$ & \pm & $<$ LOD & $\begin{array}{l}15.3 \\
0.5^{\mathrm{b}}\end{array}$ & \pm & $<$ LOD & $<$ LOD & $<$ LOD & $\begin{array}{l}13.1 \\
1.3^{\mathrm{ab}}\end{array}$ & \pm & $\begin{array}{l}8.0 \\
0.6^{\mathrm{a}}\end{array}$ & \pm & $\begin{array}{l}12.8 \\
0.7^{\text {acf }}\end{array}$ & \pm & $\begin{array}{l}5.9 \pm \\
0.4^{\mathrm{abcd}}\end{array}$ \\
\hline natural / 6 & $64 \pm 1^{\mathrm{abdg}}$ & $<$ LOD & $\begin{array}{l}7.0 \\
0.2^{c}\end{array}$ & \pm & $<$ LOD & $\begin{array}{l}16.0 \\
0.3^{b}\end{array}$ & \pm & $<$ LOD & $<$ LOD & $<$ LOD & $\begin{array}{l}12.0 \\
0.4^{\mathrm{ab}}\end{array}$ & \pm & $\begin{array}{l}8.0 \\
0.8^{a}\end{array}$ & \pm & $\begin{array}{l}14.2 \\
0.5^{\text {bcdef }}\end{array}$ & \pm & $\begin{array}{l}6.4 \pm \\
0.3^{\mathrm{abcd}}\end{array}$ \\
\hline $0 \%$ infected / 0 & $64 \pm 1^{\text {abdg }}$ & $<$ LOD & $\begin{array}{l}6.6 \\
0.1^{d}\end{array}$ & \pm & $<$ LOD & $\begin{array}{l}16.5 \\
0.1^{c}\end{array}$ & \pm & $<$ LOD & $<$ LOD & $<$ LOD & $\begin{array}{l}13.4 \\
0.4^{b c}\end{array}$ & \pm & $\begin{array}{l}8.1 \\
0.3^{\mathrm{a}}\end{array}$ & \pm & $\begin{array}{l}13.5 \\
0.3^{\mathrm{abcf}}\end{array}$ & \pm & $\begin{array}{l}6.6 \pm \\
0.4^{\mathrm{abcdg}}\end{array}$ \\
\hline $0 \%$ infected / 3 & $61 \pm 1^{c}$ & $<\operatorname{LOD}$ & $\begin{array}{l}5.4 \\
0.3^{\mathrm{a}}\end{array}$ & \pm & $<$ LOD & $\begin{array}{l}11.2 \\
0.4^{d}\end{array}$ & \pm & $<$ LOD & $<$ LOD & $<$ LOD & $\begin{array}{l}14.4 \\
0.1^{\text {bd }}\end{array}$ & \pm & $\begin{array}{l}7.8 \\
0.5^{\mathrm{a}}\end{array}$ & \pm & $\begin{array}{l}14.5 \\
0.1^{\text {bde }}\end{array}$ & \pm & $\begin{array}{l}6.5 \pm \\
0.4^{\mathrm{abcd}}\end{array}$ \\
\hline $0 \%$ infected / 6 & $63 \pm 0^{d g}$ & $<$ LOD & $\begin{array}{l}6.0 \\
0.2\end{array}$ & \pm & $<$ LOD & $\begin{array}{l}12.9 \\
0.6^{a}\end{array}$ & \pm & $<$ LOD & $<\operatorname{LOD}$ & $<$ LOD & $\begin{array}{l}13.6 \\
0.8^{\mathrm{bcd}}\end{array}$ & \pm & $\begin{array}{l}7.6 \\
0.5^{\mathrm{a}}\end{array}$ & \pm & $\begin{array}{l}14.4 \\
0.5^{\text {beg }}\end{array}$ & \pm & $\begin{array}{l}6.2 \pm \\
0.1^{\mathrm{abcd}}\end{array}$ \\
\hline $5 \%$ infected / 0 & $66 \pm 1^{a}$ & $<$ LOD & 6.4 & \pm & $<$ LOD & 21.0 & \pm & $<$ LOD & $<$ LOD & $<$ LOD & 13.0 & \pm & 8.1 & \pm & 13.0 & \pm & 6.2 \\
\hline
\end{tabular}




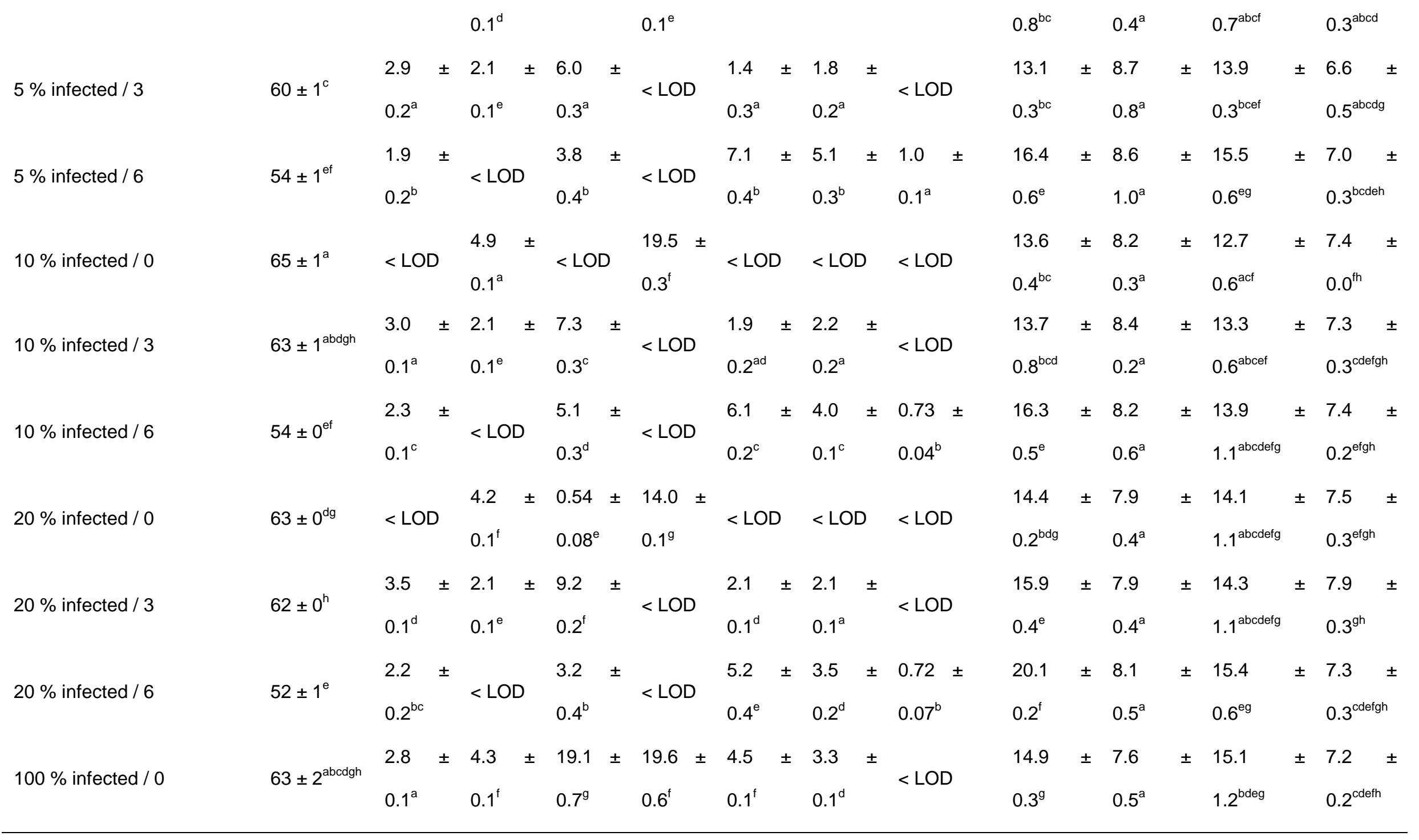


629 Table 3: Enzymatic activities of wheat samples, with method of determination ${ }^{\#}$

\begin{tabular}{|c|c|c|c|c|c|c|}
\hline $\begin{array}{l}\text { sample / weeks } \\
\text { storage }\end{array}$ & $\begin{array}{l}\text { of endo- } \beta-1,4 \text {-xylanase } \\
{[\mathrm{U} / \mathrm{kg}]}\end{array}$ & $\beta$-glucanase $[\mathrm{U} / \mathrm{kg}]$ & lipase [U/g] & protease $[\mathrm{U} / \mathrm{g}]$ & a-amylase $[\mathrm{CU} / \mathrm{g}]$ & $\beta$-amylase $[\mathrm{U} / \mathrm{g}]$ \\
\hline method & MEGAZYME@ Azo-Wheat & $\begin{array}{l}\text { MEGAZYME@ } \\
\text { Glucan }\end{array}$ & $\begin{array}{r}\text { Azo-Barley Rose and } \\
2006\end{array}$ & $\begin{aligned} \text { Pike, Brijs } & \text { et al } \\
2002 & \end{aligned}$ & $\begin{array}{l}\text { al., MEGAZYME@ } \\
\text { Ceralpha }\end{array}$ & $\begin{array}{l}\text { Hyun et al. } \\
1985\end{array}$ \\
\hline natural / 0 & $3.7 \pm 0.3^{\text {adef }}$ & $10 \pm 0^{\mathrm{ab}}$ & $2.05 \pm 0.07^{\mathrm{a}}$ & $0.50 \pm 0.02^{\mathrm{a}}$ & $11 \pm 0^{a}$ & $2.4 \pm 0.2^{\mathrm{a}}$ \\
\hline natural / 3 & $4.8 \pm 0.1^{\mathrm{bth}}$ & $11 \pm 1^{\mathrm{ab}}$ & $2.53 \pm 0.79^{a}$ & $0.32 \pm 0.03$ & $12 \pm 1^{\mathrm{abc}}$ & $2.2 \pm 0.2^{\mathrm{a}}$ \\
\hline natural / 6 & $3.0 \pm 0.1^{\mathrm{ce}}$ & $6 \pm 1^{c}$ & $1.82 \pm 0.43^{a}$ & $0.45 \pm 0.04^{a}$ & $10 \pm 1^{a b}$ & $2.2 \pm 0.1^{\mathrm{a}}$ \\
\hline $0 \%$ infected / 0 & $3.7 \pm 0.1^{\text {adef }}$ & $6 \pm 0^{c}$ & $1.22 \pm 0.23^{b}$ & $0.57 \pm 0.03^{b}$ & $10 \pm 0^{b}$ & $1.5 \pm 0.3^{b c}$ \\
\hline $0 \%$ infected / 3 & $3.6 \pm 0.5^{\text {acdet }}$ & $10 \pm 1^{\mathrm{ab}}$ & $0.45 \pm 0.04$ & $0.52 \pm 0.04^{\mathrm{ab}}$ & $13 \pm 1^{c}$ & $1.6 \pm 0.1^{\mathrm{b}}$ \\
\hline $0 \%$ infected / 6 & $3.0 \pm 0.4^{\text {ace }}$ & $13 \pm 1^{b f}$ & $1.11 \pm 0.58^{b}$ & $0.57 \pm 0.06^{\mathrm{ab}}$ & $10 \pm 1^{\mathrm{ab}}$ & $1.9 \pm 0.1^{b c}$ \\
\hline $5 \%$ infected / 0 & $4.3 \pm 0.5^{\text {befh }}$ & $7 \pm 1^{c}$ & $1.58 \pm 0.22^{b}$ & $0.48 \pm 0.03^{a}$ & $11 \pm 1^{\mathrm{abc}}$ & $3.5 \pm 0.4^{\text {deg }}$ \\
\hline $5 \%$ infected / 3 & $4.5 \pm 0.4^{\text {befh }}$ & $25 \pm 0^{d}$ & $2.44 \pm 0.36^{a}$ & $0.95 \pm 0.03^{c}$ & $39 \pm 1$ & $3.9 \pm 0.2^{\mathrm{de}}$ \\
\hline
\end{tabular}




\begin{tabular}{|c|c|c|c|c|c|c|}
\hline $5 \%$ infected / 6 & $15.6 \pm 0.8^{9}$ & $152 \pm 10^{e}$ & $7.34 \pm 1.67$ & $1.50 \pm 0.02^{\mathrm{d}}$ & $163 \pm 10$ & $5.9 \pm 0.3^{\dagger}$ \\
\hline $10 \%$ infected / 0 & $4.6 \pm 0.2^{\mathrm{bth}}$ & $14 \pm 0^{f}$ & $2.39 \pm 0.58^{\mathrm{a}}$ & $0.68 \pm 0.06$ & $16 \pm 0$ & $2.8 \pm 0.1$ \\
\hline $10 \%$ infected / 3 & $3.5 \pm 0.7^{\text {acdet }}$ & $47 \pm 1$ & $3.12 \pm 0.35^{c}$ & $1.06 \pm 0.04^{\mathrm{e}}$ & $56 \pm 1$ & $3.6 \pm 0.1^{\mathrm{dec}}$ \\
\hline $10 \%$ infected / 6 & $12.3 \pm 0.3$ & $160 \pm 3^{\mathrm{e}}$ & $13.27 \pm 0.52$ & $1.51 \pm 0.00^{d}$ & $219 \pm 7$ & $5.9 \pm 0.3^{\dagger}$ \\
\hline $20 \%$ infected / 0 & $4.6 \pm 0.3^{\mathrm{bfh}}$ & $31 \pm 2^{g}$ & $3.41 \pm 0.35^{c}$ & $1.02 \pm 0.03^{\mathrm{ef}}$ & $34 \pm 1$ & $3.2 \pm 0.1^{d}$ \\
\hline $20 \%$ infected / 3 & $6.8 \pm 0.3$ & $36 \pm 6^{g}$ & $5.35 \pm 0.58$ & $0.93 \pm 0.06^{\mathrm{cf}}$ & $81 \pm 2$ & $4.2 \pm 0.1^{\mathrm{e}}$ \\
\hline $20 \%$ infected / 6 & $16.5 \pm 0.8^{g}$ & $136 \pm 5^{\mathrm{e}}$ & $23.36 \pm 0.61$ & $1.51 \pm 0.02^{d}$ & $245 \pm 8$ & $8.5 \pm 0.2$ \\
\hline $100 \%$ infected / 0 & $4.7 \pm 0.6^{\text {beth }}$ & $70 \pm 7$ & $16.23 \pm 0.22$ & $1.15 \pm 0.05^{\mathrm{e}}$ & $374 \pm 15$ & $6.4 \pm 0.4^{\dagger}$ \\
\hline
\end{tabular}

$630{ }^{\#}$ Results shown are average values \pm confidence interval. Values in one column followed by the same upper case letter are not significantly different $631 \quad(p<0.05)$ 
632 Figure Captions:

633 Figure 1: SEM micrographs of A) natural sample week 0 overview; B) natural 634 sample week 6 overview; C) $20 \%$ infected sample week 0 overview; D) $20 \%$ 635 infected sample week 6 overview; E) natural sample week 0 endosperm; F) natural 636 sample week 6 endosperm; G) $20 \%$ infected sample week 0 endosperm; H) $20 \%$ 637 infected sample week 6 endosperm

638

639 Figure 2: Prolamins $(\mathrm{A})$ and glutelins $(\mathrm{B})$ electrophoretogram profile for the natural 640 sample week 0 (red) and the $20 \%$ infected sample week 6 (green)

641

642 

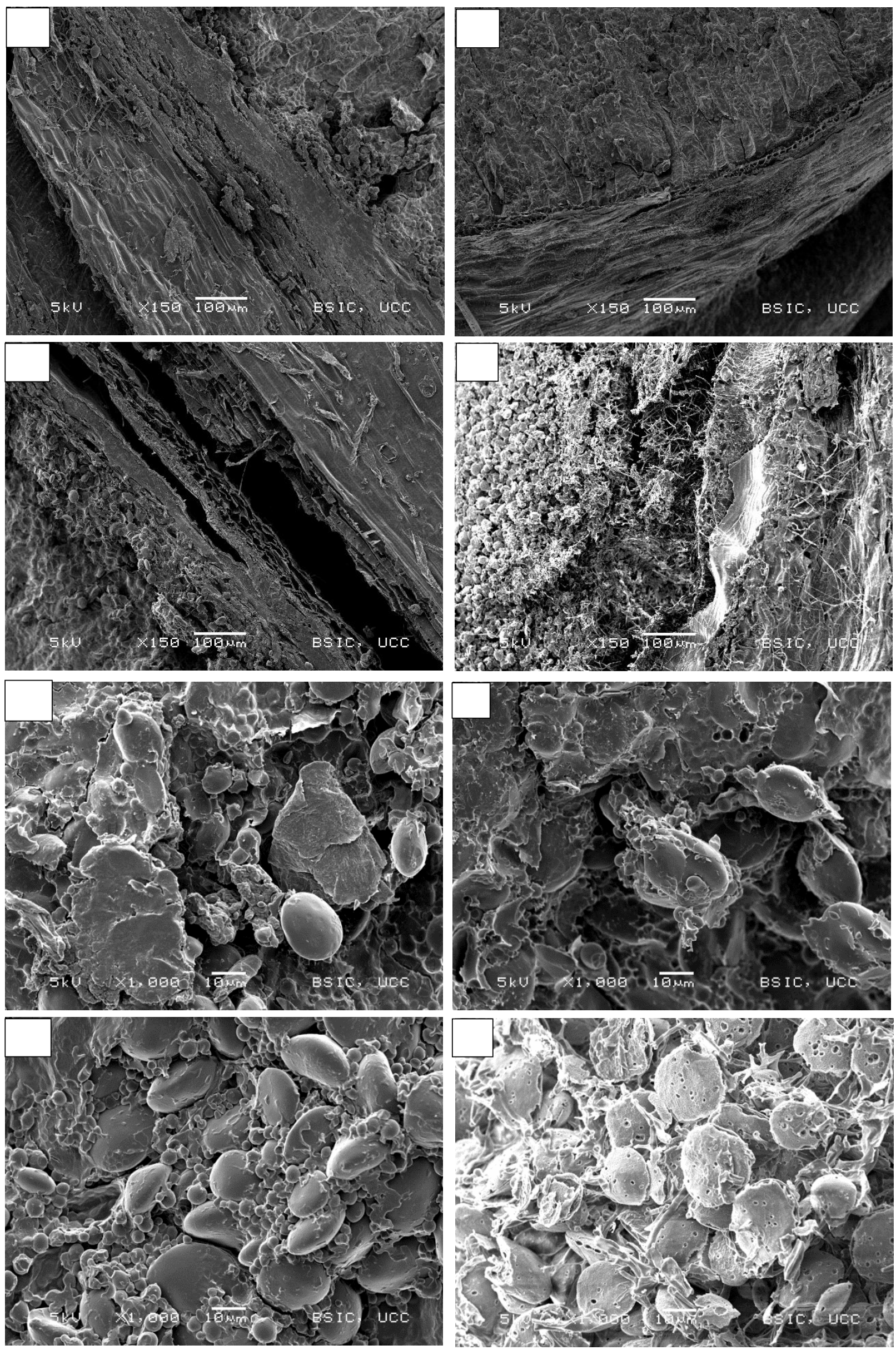
Figure 2

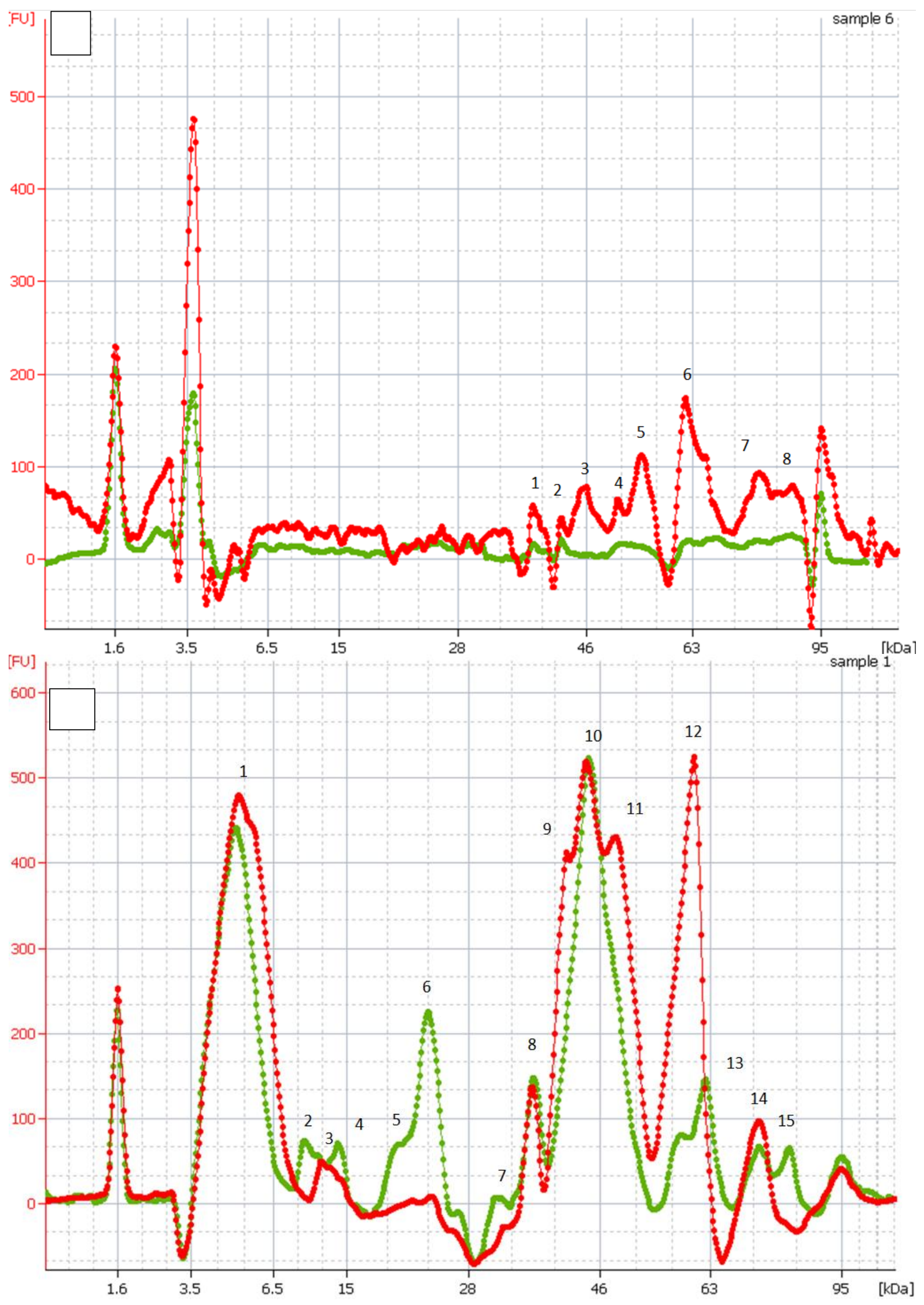

